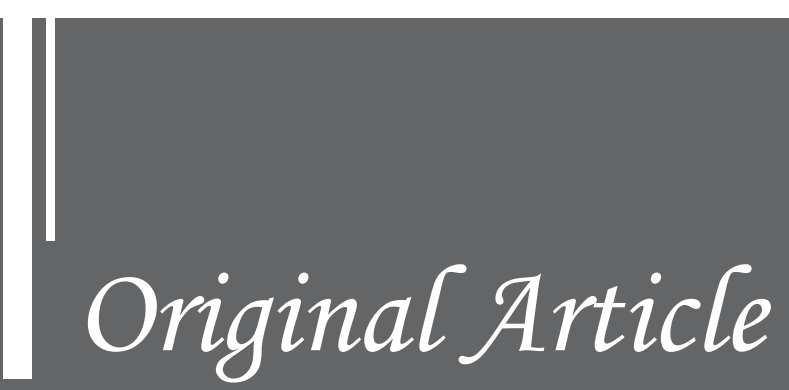

\title{
EVALUATION OF BUCKWHEAT FOR MANAGEMENT OF DIABETES
}

\author{
Anwaar Ahmed ${ }^{1}$, Humaira Rani ${ }^{1}$ Rai Muhammad Amir ${ }^{1}$, Tabinda \\ Khalid $^{2}$, Naeem Khalid ${ }^{3}$
}

${ }^{1}$ Institute of Food and Nutritional Science, PMAS-Arid Agriculture University Rawalpindi Pakistan

${ }^{2}$ Senior Registrar, Gynae/Obstetric, Rawalpindi Medical University, Rawalpindi

${ }^{3}$ Deputy Secretary Planning, Department of Agriculture, Government of Punjab, Lahore

Correspondence: Anwaar Ahmed, anwaarft@uaar.edu.pk

\begin{abstract}
Background: Diabetes mellitus is a genetic and endocrine system disease that creates injurious health effects not in Pakistan but throughout the world. Several functional compounds are present in buckwheat which has distinct biological properties of cholesterollowering, anti-hypertension, improving constipation and obesity. The recent research was directed to study the nutritional and hypoglycemic effect of buckwheat in Type 2 diabetic rats induced by alloxan.

Methods: Two varieties of buckwheat were examined for their nutritional composition and mineral content according to the methods of AACC (2000) while antioxidant activity was measured by using DPPH and a spectrophotometer. Alloxan induced diabetic mice were applied to investigate the blood-glucose-lowering effect of common buckwheat extract (CBE) and Tartary buckwheat extract (TBE). After type 2 diabetic induced rats were separated randomly into three groups.

Results: The results revealed that Common buckwheat flour (CBF) contains $12.93 \%$ crude protein, $2.39 \%$ crude fat, $9.42 \%$ crude fiber and $2.90 \%$ ash content, while Tartary buckwheat flour (TBF) contains $14.88 \%$ crude protein, $3.47 \%$ crude fat, $12.03 \%$ crude fiber, and $2.86 \%$ ash content. TBF contains significantly higher minerals as compared to CBF and also exhibited higher antioxidant activity. The results for diabetes-induced mice showed a significant difference for fasting blood glucose level, glucose tolerance test and body weight among control diabetic mice (group I) and diabetic mice given the CBE (group II) and TBE (group III). The fasting blood glucose level of group I increased while it decreased in group II and group III over time. Group II and group III had more glucose tolerance as compared to group I.

Conclusion: The present study demonstrated that TBF contains higher nutritional contact as compared to CBF. Furthermore, it was indicated that the oral administration of CBE and TBE could lower the blood glucose level and can increase glucose tolerance effectively.

Keywords: Common buckwheat, tartary buckwheat, blood glucose level, glucose tolerance test
\end{abstract}




\section{Introduction}

Buckwheat, also called triangle wheat is a pseudocereal that belongs to the family Polygonaceae and genus Fagopyrum. It is not a true cereal so it places in the group of pseudo-cereal due to its close resemblance to conventional cereals for its use and composition (1). There are numerous species of buckwheat out of which only nine species are used for the agricultural purpose and out of these nine species, only two are used as food which is common buckwheat (Fagopyrumesculentum) and the Tartary buckwheat (Fagopyrumtataricum) (2). Its cultivation is limited in Pakistan which is bound to the mountain regions of GilgitBaltistan at sea level of 2000-3200 meter (3). In Pakistan, its yield was documented in the range of $1221 \mathrm{~kg} / \mathrm{ha}$ without fertilization and with the application of fertilizers its yield was $1796 \mathrm{~kg} / \mathrm{ha}$ (4). Several functional compounds present in buckwheat tissues and seeds. The key compounds are dietary fiber, polysaccharides, lipids, polyphenols, rutin, proteins and micronutrients such as vitamins and minerals $(5,6)$. Phenolic compounds in buckwheat also hold antioxidant activities (7, $8,9)$. The protein of buckwheat has an exclusive amino acid composition, distinct biological activities of cholesterol-lowering effect, anti-hypertension effect, improving constipation and obesity condition $(10,11)$. It is used as a hypotensive and anti-hemorrhagic drug. It is also used for the cardiovascular disorder (12). For the treatment of type II diabetes, buckwheat is commonly used as it can lower the blood sugar level of type II diabetic patients $(13,14)$. It comprises of D-chiro-inositol that is necessary for insulin signal transduction in a secondary messenger pathway that is lacked in type II diabetes. Tartary buckwheat has a tendency for the cure of type 2 diabetes $(15,16)$. D-Chiro-inositol is naturally present in buckwheat seed.

Diabetes mellitus is a genetic and endocrine system disease that creates injurious health effects not in Pakistan but throughout the world (17). Diabetes mellitus has been classified into two categories type 1 that is insulin-dependent and type 2 are non-insulin dependent (18). A global survey has already suggested that around the world about 415 million peoples are affected with diabetics and this figure may be exceeded in this year to 640 million (19). Type 2 diabetes is most common and about more than $90 \%$ people are diagnosed with it and various cure methods have been applied for this purpose like synthetic hypoglycemic agents and biguanides. Considerable progress has been made in orthodox antidiabetic drugs. New remedies are still in great demand because of the limited efficacy and undesirable side effects of current orthodox drugs $(20,21)$. The buckwheat also has the potential to treat hypoglycemic and hypolipidemic effects in type 2 diabetic rats and can be a potential candidate for investigation as an anti-diabetic agent in humans. It has been found from the previous studies that buckwheat has various pharmacological activities such as antioxidant, neuroprotective, anti-cancer, anti-hypercholesterolemia and antihypertensive.

Therefore, it is desired to manage the effects of diabetes from some natural sources like buckwheat. Our study aimed at the characterization and nutritional evaluation of common and Tartary buckwheat flour preparations to find out the hypoglycemic effects in the management of diabetes.

Methodology

Two varieties of buckwheat (Common and Tartary) were procured from Skardu, Pakistan. To make flour, grains were ground in laboratory mill (Perten Instruments, Vietnam)at Grain Quality Testing Laboratory, NARC, Islamabad.

\section{Nutritional Analysis}

The chemical analysis includes moisture contents, crude protein contents, crude fiber contents, crude fat contents, ash contents and NFE (nitrogen-free extract). The moisture contents were analyzed through the oven drying method at temperature $130 \pm 2^{\circ} \mathrm{C}$ for 1 hour to gain the fixed weight of the sample. The crude protein contents were evaluated by the Khejdhal method and fat contents were determined by the Soxhlet apparatus. The ash contents were assessed by using the muffle furnace (Nabertherm GmbH, Germany) at a temperature of about 550 to $600 \mathrm{OC}$ for six hours to the obtained constant weight of the ash. The fiber contents were determined by using acid and alkali for digestion purposes. The number of minerals in flour (Iron, Zinc, Manganese, Copper, and Magnesium) were determined by Atomic absorption spectrophotometer according to AACC Method (22). Samples were digested (wet digestion) into a wet digester unit before running through Atomic Absorption Spectrophotometer. While antioxidant activity was determined by using DPPH and spectrophotometer at a wavelength of $517 \mathrm{~nm}(23)$.

Preparation and analysis of Common and Tartary Buckwheat Extract (BE)

For the extraction of buckwheat grain powder, Yao et al. method was used with some modifications. The extraction of buckwheat grain powder was done with $60 \%$ ethanol aqueous solution for 70 minutes at $50^{\circ} \mathrm{C}$. After filtration with filter paper, the rotary evaporator was used for removal of solvent and the one-third concentration of filtrate was obtained. Then it was stored at $4{ }^{\circ} \mathrm{C}$ until use (24). The crude protein of extracts was determined by the Kjeldahl method and carbohydrate was determined by the titration method as described in the food chemical codex (25).

Animal Studies

To investigate the glucose-lowering effect of buckwheat, animal studies were performed using mice (Sprague Dawley) as an experimental model and were procured from NIH, Islamabad, Pakistan. Before grouping, mice were acclimatized with the environment, providing with ad-labitum water and feed (standard formula feed for mice). Fifteen mice were divided into three groups: group I, control diabetic animals $(\mathrm{n}=5)$; group II $(\mathrm{n}=5)$ diabetic animals fed common buckwheat extract at the dose rate of $182 \mathrm{mg} / \mathrm{kg}$ body weight; group III $(\mathrm{n}=5)$ diabetic animals fed Tartary buckwheat extract at the dose rate of $182 \mathrm{mg} / \mathrm{kg}$ body weight. All mice were kept into individual specially designed cages under a standard condition of temperature $(23 \pm 10 \mathrm{C})$ and 12 hours of light and dark cycle.

\section{Preparation of Alloxan-Induced Diabetic Mice}

Mice were induced with diabetes by following the method of Li et al. Briefly, after 7 days and over-night fasting, alloxan was injected intraperitoneal in mice at a dose of $200 \mathrm{mg} / \mathrm{kg}$ body weight. After the 3rd day of injection, diabetes was confirmed by taking the blood glucose level from the tail vein. After confirmation of high blood glucose levels, diabetic mice were kept for 21 days and treated with different doses of common and Tartary buckwheat extract daily as described above (26).

\section{Fasting Blood Glucose Levels}

After each week and three times in the whole experiment, blood samples were obtained after overnight fasting from the tail vein and processed for blood glucose analysis through glucose analyzer (ACCU-CHECK, Roche, US) using the specific glucose measuring instrument strip (27).

\section{Glucose Tolerance Test (GTT)}

For GTT, fasting animals were injected intra-peritoneal glucose (Concentration of glucose $25 \%$ ) at the dose rate of $0.2 \mathrm{ml} / 40 \mathrm{~g}$. Blood glucose levels were measured at $0,15,45$ and $120 \mathrm{~min}$ after glucose administration.

Statistical Analysis

Statistical analysis was used to determine the level of significance and difference in mean. The data obtained from the compositional and functional analysis of two Buckwheat varieties were analyzed using ttest at $5 \%$ level of significance $(\mathrm{p}<0.05)$. The data obtained from the biological study of the Buckwheat extracts used on Albino Rats was analyzed in 2- factor factorial design under a Completely Randomized Design arrangement. LSD for comparison of mean was applied by using software Statistics 8.1.(28).

Results

\section{Chemical Composition}

The chemical composition of two varieties of buckwheat (common and Tartary) has been given in table 1 . The data revealed that crude protein, crude fat, crude fiber was significantly higher in Tartary buckwheat flour as compared with common buckwheat flour. But, there was no significant difference between the ash and moisture content of two varieties of buckwheat flour. Additionally, the nitrogen-free extract was significantly higher in common buckwheat flour then Tartary buckwheat flour. 
Table 1: Chemical composition of common and Tartary buckwheat flour

\begin{tabular}{|l|c|c|}
\hline Proximate composition & Common Buckwheat & Tartary Buckwheat \\
\hline Moisture \% & $10.61 \pm 0.049 \mathrm{a}$ & $10.345 \pm 0.101 \mathrm{a}$ \\
\hline Protein \% & $11.90 \pm 0.886 \mathrm{~b}$ & $13.68 \pm 0.199 \mathrm{a}$ \\
\hline Fat \% & $2.396 \pm 0.016 \mathrm{~b}$ & $3.4731 \pm 0.537 \mathrm{a}$ \\
\hline Fiber \% & $9.424 \pm 0.572 \mathrm{~b}$ & $12.034 \pm 0.709 \mathrm{a}$ \\
\hline Ash\% & $2.9053 \pm 0.117 \mathrm{a}$ & $2.863 \pm 0.519 \mathrm{a}$ \\
\hline NFE\% & $62.62 \pm 1.906 \mathrm{a}$ & $57.55 \pm 1.314 \mathrm{~b}$ \\
\hline
\end{tabular}

Similar results were observed in previous studies for moisture content in Tartary buckwheat that was $10.2 \%$ while in common buckwheat it was $9.8 \%(29,30)$. This variation is because moisture content mainly depends upon the environmental condition in which crop is grown. The above results for crude protein are in line with the results of Qin et al. (6) who reported that Tartary buckwheat flour has $6.82-15.02 \%$ protein contents that were higher compared with common buckwheat flour that contained $8.06-12.44 \%$ protein. The quantity and quality of buckwheat flour depend on many factors including the variety of buckwheat, type of pesticide and fertilizer that affects the concentration of protein in buckwheat (31). The results obtained for fat content in common buckwheat flour and Tartary buckwheat flour are in line with the results of Sonia et al. who reported higher fat content in Tartary buckwheat compared with the common buckwheat (32). But, many researchers reported almost equal values for the fat content of both varieties of buckwheat flour $(6,29)$. The differences between fat contents may be due to various seeding times, differed in cultivars and growth location (33). The results of present study regarding ash content of flour were found to be in conformance with the findings of Lin et al. and Qin et al. who reported that the common buckwheat flour contained $2.2 \%$ ash content and Tartary buckwheat flour has also the same value $(2.2 \%)$ for ash content $(6,34)$. These results for nitrogen-free extract are in line with the findings of Qin et al. and Ogungbenle who reported that the nitrogen-free extract in common buckwheat flour was higher $(73.3 \%)$ compared to in Tartary buckwheat flour in which it was $70.3 \%$. $(6,35)$

\section{Minerals Contents}

The results of the minerals contents of common buckwheat flour and Tartary buckwheat flour have been shown in table 2 . The experimental results depicted that the minerals contents in Tartary buckwheat flour (Fe 127.11ppm, Zn 13.811ppm, Mg 2322.7ppm, Mn 10.585ppm, Cu $7.255 \mathrm{ppm}$ ) was significantly (p ? 0.05) higher than the minerals content in common buckwheat flour (Fe 113.89ppm, Zn 10.72ppm, Mg 1560ppm, $\mathrm{Mn} 8.74 \mathrm{ppm}$ and $\mathrm{Cu} 5.726 \mathrm{ppm})$.

Table 2: Mineral composition of common and Tartary buckwheat flour (ppm)

\begin{tabular}{|l|c|c|}
\hline Mineral Composition & Common Buckwheat & Tartary Buckwheat \\
\hline Iron $(\mathrm{Fe})$ & $113.89 \pm 1.063 \mathrm{~b}$ & $127.11 \pm 1.334 \mathrm{a}$ \\
\hline Zinc $(\mathrm{Zn})$ & $10.78 \pm 0.955 \mathrm{~b}$ & $13.811 \pm 0.939 \mathrm{a}$ \\
\hline Magnesium $(\mathrm{Mg})$ & $1560.3 \pm 1.357 \mathrm{~b}$ & $2322.7 \pm 3.856 \mathrm{a}$ \\
\hline Manganese $(\mathrm{Mn})$ & $8.473 \pm 0.512 \mathrm{~b}$ & $10.585 \pm 0.508 \mathrm{a}$ \\
\hline Copper $(\mathrm{Cu})$ & $5.7267 \pm 0.447 \mathrm{~b}$ & $7.2533 \pm 0.564 \mathrm{a}$ \\
\hline
\end{tabular}

These findings are in line with the results of Zhang and $\mathrm{Hu}$ and Lin et al who reported more minerals contents in Tartary buckwheat compared to common buckwheat. Buckwheat has been identified that has more mineral contents (except $\mathrm{Ca}$ ) than other cereals and they perform a vital role in the human body $(36,37)$

Antioxidant Activity

Statistical results demonstrate that a significant $(\mathrm{p}<0.05)$ difference was observed in the DPPH radical scavenging activity of common and Tartary buckwheat extract (Fig 1). The DPPH radical scavenging activity increased as the concentration of the sample increased. DPPH radical scavenging activity of Tartary buckwheat extract was maximum at the concentration $800 ? \mathrm{~g} / \mathrm{ml}$ that was $67.46 \%$ and in case of common buckwheat extract in which it was $58.50 \%$.

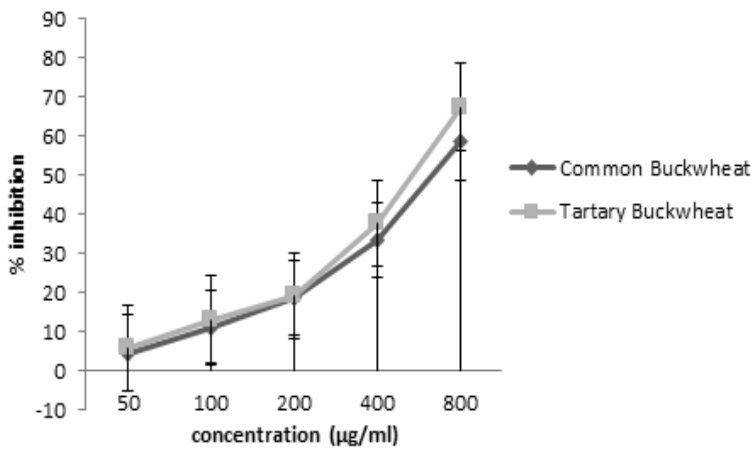

Fig 1: antioxidant activity of common and Tartary buckwheat flour at different concentrations

As different antioxidant compounds are found in buckwheat so a higher concentration of antioxidant radicals was observed. Between two varieties, the best results were shown by Tartary buckwheat $(67.46 \%)$.

The results are in line with the results of Abbasi et al. who reported the antioxidant potential of buckwheat at different concentrations cultivated in Chitral (38). The findings are also in line with the findings of Sonia et al. who reported the F. tataricum has more antioxidant activity as compared to F. esculuntum (32).

Composition of Buckwheat Extract

The carbohydrate, protein and moisture content of buckwheat extract are given in table 3 . The carbohydrates content in common buckwheat extract was significantly higher as compared to Tartary buckwheat extract. While moisture and protein content was higher in Tartary buckwheat extract. Similar findings were reported by other studies regarding Tartary buckwheat bran extract and Tartary buckwheat flavonoid extract $(39,40)$.

Table 3: Chemical composition of common and Tartary buckwheat extract

\begin{tabular}{|l|c|c|}
\hline \multicolumn{1}{|c|}{ Chemical composition } & Common Buckwheat & Tartary Buckwheat \\
\hline Carbohydrates \% & $0.593 \pm 0.025 \mathrm{a}$ & $0.366 \pm 0.060 \mathrm{~b}$ \\
\hline Protein \% & $5.43 \pm 0.277 \mathrm{~b}$ & $6.68 \pm 0.503 \mathrm{a}$ \\
\hline Moisture \% & $4.393 \pm 0.692 \mathrm{~b}$ & $5.983 \pm 0.526 \mathrm{a}$ \\
\hline
\end{tabular}

\section{GLUCOSE LOWERING EFFECT OF BUCKWHEAT}

\section{Fasting blood glucose level}

Buckwheat extract has the potential to lower glucose in mice induced with alloxan shown in fig 2 . The statistical results exhibited that there was a substantial variation between control (group I) and experimental groups (group II and group III) for the fasting blood glucose levels of mice. At first-day glucose increment after the administration of alloxan was $67 \%$ of the normal blood glucose level in control diabetic mice (group I) while in diabetic mice given the CBE (group II) and diabetic mice given the TBE (group III) this increment was $84 \%$ and $67 \%$ as compared to normal blood glucose level respectively. After twenty-one days, the blood glucose level was increased $139 \%$ in group I. The difference of increment of the blood glucose level of group I between the first and twenty-one days was $94 \%$. While in group II and group III blood glucose level was decreased with time. The difference of decrement of the blood glucose level of group II between the first and twenty-one days was $45 \%$. The difference of decrement of the blood glucose level of group III between the first and twenty-one days was $28 \%$. Group, I had the highest blood glucose level as compared to group II and group III. In group I, blood glucose level was increased as the time increased while in group II and group III, it was decreased as the time increases. From these results, it is clear that the buckwheat 
extract that was given the group II and group III is effective for lowering blood glucose level as compared to the group I.

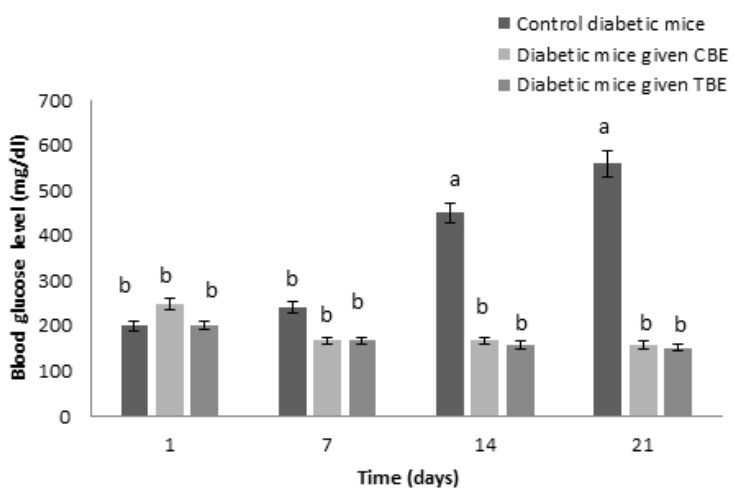

Fig 2: Fasting blood glucose level of alloxan-induced diabetic mice given oral doses of $\mathrm{CBE}$ and TBE compared with control of diabetic mice. The values are given as mean \pm SD of 5 animals.

Glucose Tolerance Test

Buckwheat extract was appeared to improve glucose tolerance in diabetic mice fig 3 . The statistical results exhibited that there was a significant difference between control (group I) and experimental groups (group II and group III) for the glucose tolerance test of mice while the interaction between the experimental groups that were group II and group III was found to be non-significant. The blood glucose level of control diabetic mice sharply increased at $45 \mathrm{~min}$ and then this increment remained persistent for the next $75 \mathrm{~min}$. CBE and TBE treated diabetic mice of group II and III showed more decreases in blood glucose levels at 45 and $120 \mathrm{~min}$ as compared to control diabetic mice of group I.

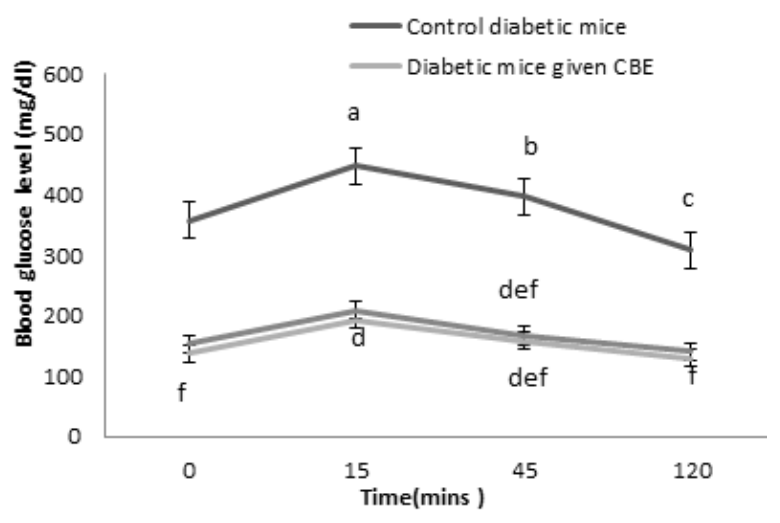

Fig 3: Oral glucose tolerance test in alloxan-induced diabetic mice given oral doses of CBE and TBE compared with control diabetic mice at week 3 . The values are given as mean $\pm \mathrm{SD}$ of 5 animals. Body Weight

It was observed that the bodyweight of the control diabetic group decreased with time as compared to the experimental group in which the bodyweight increases with time (Fig 4). The results obtained depicted that the bodyweight showed a significant difference $(p<0.05)$ between the control and experimental group but there was a nonsignificant difference between two experimental groups (group II and group III). The overall $28.28 \%$ decrease in body weight was observed at day twenty-one as compared to the first day. The slight increase in mice's body weight was observed in the experimental group with time. As far as group II and III was concerned, $5.909 \%$ and $5.64 \%$ increase in body weight was observed, respectively. There was a significant difference between the control group and the experimental groups. The hypolipidemic and hypoglycemic effects of Tatary buckwheat significantly reduces serum insulin and fasting blood glucose and conclusively increased body weight along with boost glucose intolerance in type 2 diabetic rats. Furthermore, the good quality protein of buckwheat might be responsible in increasing the body weight of experimental rats.

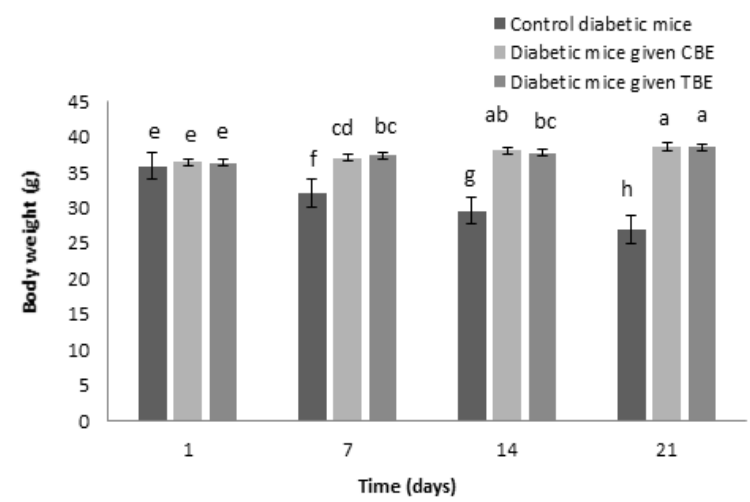

Fig 4: Bodyweight of alloxan-induced diabetic mice given oral doses of CBE and TBE compared with control of diabetic mice. The values are given as mean \pm SD of 5 animals.

\section{Discussion}

The blood glucose level of mice reduced significantly after oral administration of buckwheat extract as the buckwheat contains Dchiro-inositol which has the insulin-like activity and it improved the insulin resistance (15). Previous studies have shown that buckwheat bran extract can lower blood glucose levels (40). The laboratory animals and humans experimental studies indicated that buckwheat flour can improve obesity, high blood pressure, diabetes, and higher cholesterol levels (10). The D-chiro-inositol in buckwheat has been identified an indispensable factor in the secondary messenger route for insulin signal transduction. The patients with Type 2

diabetes have a deficiency of D-chiro-inositol (13). During a study with rats, D-chiro-inositol has been proved to reduce elevated glucose blood levels. The Syringic acid, p-hydroxybenzoic acid, p-coumaric acid, vanilic acid, and proanthocyanidins have been reported to have been observed in the aleurone layer of the bran have profound impact on serum glucose (41)

The results are also in line with the study of Kawa et al. who revealed the effect of buckwheat concentrate reduced serum glucose in streptozotocin diabetic rats (13). Another study showed that Tartary buckwheat bran extract that was rich in DCI was more effective in the reduction of the blood glucose level of diabetic rats. A similar trend was seen in our research in which buckwheat extract lowered the blood glucose level. The findings of our research are according to the findings of Li et al. who reported a similar trend for glucose tolerance in which glucose level reaches the peak after $30 \mathrm{~min}$ of oral glucose administration and then it starts to decline (14). The control group was more resistant to decline compared to groups that were treated with a buckwheat diet. The results are also in line with the findings of Yao et al. who reported that buckwheat bran extract that contained DCI can lower the glucose level in the blood (40). The results of recent study are similar to previous findings conducted on rats. The hypoglycemic effect of buckwheat flour was investigated by previous researchers who found a positive correlation in diabetic rats $(42,43)$.

Conclusion

This study demonstrates that the buckwheat extract is effective for glucose-lowering activity as the previous research revealed that buckwheat has fagopyritol that is the derivative of D-chiro-inositol having insulin-like activity. Therefore, the use of common buckwheat and Tartary buckwheat in the diet might be useful in the treatment of diabetes. 


\section{References}

1 .

Campbell, C. G. 1997. Buckwheat Fagopyrumesculentum Moench. Promoting the Conservation and Use of Underutilized and Neglected Crops.vol. 19.Biodiversity International Rome, Italy.95 pp.

2. Krkoskova, B., and Z. Mrazova. 2005. Prophylactic components of buckwheat. Food Res. Int., 38: 561-568

3. Ohnishi, O. 1994.Buckwheat in Karakoram and the Hindukush.Fagopyrum, 14: 17-25.

4. Inamullah, G. Saqib, M. Ayub, A. A. Khan, S. Anwar and S A. Khan. 2012. Response of common buckwheat to nitrogen and phosphorus fertilization. Sarhad J. Agric., 28: 171-178.

5. Kim, S. L., S. K. Kim and C. H. Park. 2004. Introduction and nutritional evaluation of buckwheat sprouts as a new vegetable. Food Res. Int., 37: 319-327.

6. Qin, P., Q. Wang, F. Shan, Z. Hou and G. Ren. 2010 Nutritional composition and flavonoids content of flour from different buckwheat cultivars. Int. J. Food Sci. Tech., 45: 951-958.

7. Holasova, M., V. Fiedlerova, H. Smricinova, M. Orsak, J. Lachman, S. Vavreinova. 2002. Buckwheat - the source of antioxidant activity in functional foods. Food Res. Int., 35: 207-211

8. Sun, T. and C. T. Ho. 2005.Antioxidant activities of buckwheat extracts. Food Chem., 90: 743-749.

9. Sensoy, I., R. T. Rosen, C. T. Ho and M. V. Karwe. 2006 Effect of processing on buckwheat phenolic and antioxidant activity. Food Chem., 99: 388-393

10. Li, S. Q. and Q. H. Zhang. 2001. Advances in the development of functional foods from buckwheat. Crit. Rev. Food Sci. Nutr., 41: 451-464.

11. Zhang, C., R. Zhang, Y. M. Li, N. Liang, Y. Zhao, H. Zhu, Z He, J. Liu, W. Hao, R. Jiao. 2017. Cholesterol-lowering activity of Tartary buckwheat protein. J. Agric. Food Chem., 65(9): 1900-1906.

12. Kreft, M. 2016. Buckwheat phenolics metabolites in health and disease. Nutri. Res. Review, 1-10

13. Kawa, M. J., C. G. Taylor and R. Przybylski. 2003. Buckwheat concentrate reduces serum glucose in streptozotocin-diabetic rats. J. Agric. Food Chem., 51: 7287-7291.

14. Li, J., F. Gong, F. Li. 2016. Hypoglycemic and hypolipidemic effects of flavonoids from Tartary buckwheat in type 2 diabetic rats. Biomedi. Res., 27 (1): 132-137.

15. Lu, L. C., Q. Zheng, Q. Shen, C. Song and Z. M. Zhang. 2017. Uncovering the relationship and mechanisms of Tartary buckwheat (Fagopyrumtataricum) and Type II diabetes, hypertension, and hyperlipidemia using a network pharmacology approach. PEERJ, 5: 1-17.

16. Hu, Y., Z. Hou, R. Yi, Z. Wang, P. S?un, G. Li, X. Zhao and Q. Wang. 2017. Tartary Buckwheat Flavonoids Ameliorate High Fructose-Induced Insulin Resistance and Oxidative Stress associated with the insulin signaling and Nrf2/HO-1 pathways in mice. Food Funct., 2017: 1-35.

17. Chen, X., J. Jin, J. Tang, Z. Wang, J. Wang, L. Jin and J. Lu. 2011. Extraction, purification, characterization and hypoglycemic activity of a polysaccharide isolated from the root of Ophiopogonin japonicus. Carbohydr.Polym., 83: 749-754.

18. Chen, J., W. L. Li, J. L. Wu, B. R. Ren and H. Q. Zhang. 2008. Hypoglycemic effects of a sesquiterpene glycoside isolated from leaves of loquat. Phytomed., 15:98-102.

19. IDF Diabetes Atlas. 2015. International Diabetes Federation, 7th ed., Brussels, Belgium.

20. Chang, C. L., Y. Lin, A. P. Bartolome, Y. C. Chen, S. C. Chiu and W. C. Yang. 2013. Herbal therapies for type 2 diabetes mellitus: chemistry, biology, and potential application of selected plants and compounds. Evid. Based Compl.Altern. Med., 2013: 1-33.

21. Derosa, G., C. P. Limas, P. C. Macías, A. Estrella and P. Maffioli. 2014. Dietary and nutraceutical approach to type 2 diabetes. Arch. Med. Sci., 10(2):336-344.
22. AACC 2000. Approved Methods of the American Association of Cereal Chemists, 10th ed., American Association of Cereal Chemists, Arlington, USA.

23. Chen, Y., F. M. Wang, T. R. Rosen and T. C. Ho. 1999.2, 2 Diphenyl-1-picryl- hydroxyl radical-scavenging active components from PolygonummultiflorumThunb. J. Agric. Food Chem., 47: 2226-2228.

24. Yao, Y., G. Ren, J. S. Wang, F. Chen and M. F. Wang. 2008 Antidiabetic activity of mung bean extracts in diabetic mice. J. Agric. Food Chem., 56: 8869-8873

25. FCC. 1996. Food Chemical Codex. First Supplement National Academic Press, p. 18

26. Li, F., H. Tang, F. Xiao, J. Gong, Y. Peng and X. Meng. 2011. Protective effect of salidroside from rhodiolae radix on diabetes-induced oxidative stress in mice. Mol., 16(12): 9912-9924.

27. Jemai, H., E. El-Feki and S. Sayadi. 2009. Antidiabetic and antioxidant effects of hydroxytyrosol and oleuropein from olive leaves in alloxan-diabetic rats. J. Agri. Food Chem. 57(19): 8798-8804.

28. Steel, G. D., H. Torrie and D. Dickey. 1997. Principles and Procedures of Statistics. A Biometrical Approach.3rd ed., McGraw Hill Book Co., NY. USA.

29. Bonafaccia, G., and N. Fabjan. 2003. Nutritional comparison of Tartary buckwheat with common buckwheat and minor cereals. Acta Agri. Slovencia, 81:349-355.

30. Przybylski, R. and E. Gruczynska 2009.A review of nutritional and nutraceutical components of buckwheat.Europ. J. Plant Sci. Biotech., 3: 10-22

31. Fornal, L. 1999. The chemistry of seed lines grykii food use. Sci. News., 4: 7-17.

32. Sonia, M., D. Gupta, R. K. Gupta. 2012. Evaluation of nutritional and antioxidant potential of Indian buckwheat grains. Indian J. Tradit.Know., 11: 40-44.

33. Tsuzuki, W., Y. Ogata, K. Akasaka, S. Shibata, and T. Suzuki. 1991. Fatty acid composition of selected buckwheat species by fluorometric high-performance liquid chromatography. Cereal Chem., 68:365-369

34. Lin, L. Y., H. M. Liu, Y. W. Yu, S. D. Lin and J. L.Mau. 2009. Quality and antioxidant property of buckwheat enhanced wheat bread. Food Chem., 112: 987-991.

35. Ogungbenle, H. N. 2003. Nutritional evaluation and functional properties of quinoa (Chenopodium quinoa) flour. Int. J. Food Sci. Nutri., 54: 153-158.

36. Zhang, M. L. and X. S. Hu. 2004. Research advance of buckwheat biological active substance and function. Rainfed Crops Chin., 24: 26 -29.

37. Lin, R. F., X. L. Zhou, G. X. Ren, J. S. Bian, F. Shan. 2005 Production and trading of buckwheat in China, nutrition and food. Food Sci., 26:259-263.

38. Abbasi, R., S. Janjua, A. Rehman, K. William and S. W. Khan. 2015. Some preliminary studies on phytochemicals and antioxidant potential of Fagopyrumesculentum cultivated in Chitral, Pakistan. J. Anim. Plant Sci., 25: 576579.

39. Bian, J., F. Shan, Z. Tian, G. Xu, R. Lin, X. Chunsheng, D.Yali, J.Mingjie. 2004. Study on new health foods of Tartary buckwheat. In: Proceedings of the 9th International Symposium on Buckwheat. Prague: pp714-718.

40. Yao, Y., G. Ren, J. S. Wang, F. Chen and M. F. Wang. 2008 Antidiabetic activity of mung bean extracts in diabetic mice. J.Agric. Food Chem., 56: 8869-8873.

41. Asplin I, Galasko G, Larner J. chiro-Inositol deficiency and insulin resistance: a comparison of the chiro-inositol- and the myo-inositol-containing insulin mediators isolated from urine, hemodialysate, and muscle of control and type II diabetic subjects. Proc Natl Acad Sci USA. 1993;90(13):5924-5928.

42. Kim, K., Kim, H. Kwon, J. Lee, S. Kong. H. Im, S.A. Lee, Y.H. Lee, Y.R. Oh, S.T. Jo, T.H. Park, Y.I. Lee and C.K. Kim (2009). Hypoglycemic and hypolipidemic effects of processed Aloe Vera gel in a mouse model of non-insulindependent diabetes mellitus. Phytomedicine, 16: 856-863. 
43. Lemke, L.B., A.B. Rogers, P.R Nambiar and J.G Fox.

Obesity and non-insulin-dependent diabetes mellitus in

Swiss-Webster mice associated with late-onset

hepatocellular carcinoma. J. Endocrinol. 2008: 199:21-32. 